University of Rhode Island

DigitalCommons@URI

Open Access Master's Theses

1992

\title{
The Coping Strategies of Taiwanese Students at an American University
}

Litsong Lu

University of Rhode Island

Follow this and additional works at: https://digitalcommons.uri.edu/theses

\section{Recommended Citation}

Lu, Litsong, "The Coping Strategies of Taiwanese Students at an American University" (1992). Open Access Master's Theses. Paper 1582.

https://digitalcommons.uri.edu/theses/1582

This Thesis is brought to you for free and open access by DigitalCommons@URI. It has been accepted for inclusion in Open Access Master's Theses by an authorized administrator of DigitalCommons@URI. For more information, please contact digitalcommons-group@uri.edu. 
THE COPING STRATEGIES OF TAIWANESE STUDENTS

AT AN AMERICAN UNIVERSITY

BY

LITSONG LU

A THESIS SUBMITTED IN PARTIAL FULEILLMENT OF THE REQUIREMENTS FOR THE DEGREE OF

MASTER OF ARTS

IN

EDUCATION

$283554 \div 4$

UNIVERSITY OF RHODE ISLAND

1992 
ABSTRACT

Review of literature suggests that studies of coping strategies used by international students in their crosscultural adjustment were needed. Using interview and qualitative methodology, this study investigated the coping strategies of 24 international students from Taiwan at a small university on the northeast coast of the United states of America. A personally administered questionnaire was developed and used to obtain the demographic information and the cross-cultural adjustment experience. A in-depth interview was conducted to gather more details. The data was coded and analyzed qualitatively. The results are presented in major categories including individual problem-solving, information-seeking, support-seeking and inaction lattentive inaction, passive inaction and temporary inaction).

Lack of essential information and support from the host environment, students solve their problem in their own way. Implications for institutional facilitation and instructors / advisors as well as for future research were recommended. 


\section{ACKNOWLEDGMENTS}

To U-Ser

To my parents and parent-in-laws

I would like to thank Professor James Barton and John Boulmetis for their guidance and constant support in my cross-cultural academic experience. I would like to thank Professor Chen for his valuable advice on my research. I would like to send my special thanks to all my subjects for their contribution in this study. 


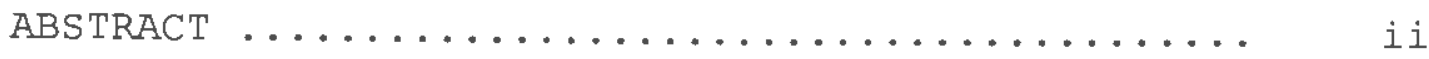

ACKNOWLEDGMENTS $\ldots \ldots \ldots \ldots \ldots \ldots \ldots \ldots \ldots \ldots \ldots \ldots \ldots \ldots \ldots \ldots$ ii

TABLE OF CONTENTS $\ldots \ldots \ldots \ldots \ldots \ldots \ldots \ldots$ iv

LIST OF FIGURES $\ldots \ldots \ldots \ldots \ldots \ldots \ldots \ldots \ldots \ldots \ldots$ v

1. INTRODUCTION

BACKGROUND $\ldots \ldots \ldots \ldots \ldots \ldots \ldots \ldots \ldots \ldots \ldots \ldots$

REVIEW OF LITERATURE $\ldots \ldots \ldots \ldots \ldots \ldots \ldots \ldots$. 3

STATEMENT OF THE RESEARCH QUESTION $\ldots \ldots \ldots \ldots$. 6

2. METHOD

SUBJECT $\ldots \ldots \ldots \ldots \ldots \ldots \ldots \ldots \ldots \ldots \ldots \ldots \ldots \ldots \ldots \ldots \ldots$

INSTRUMENTATION $\ldots \ldots \ldots \ldots \ldots \ldots \ldots \ldots \ldots$

PROCEDURE

DATA COLLECTION $\ldots \ldots \ldots \ldots \ldots \ldots \ldots \ldots$

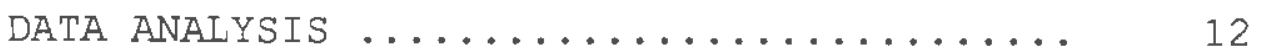

3. RESULTS $\ldots \ldots \ldots \ldots \ldots \ldots \ldots \ldots \ldots \ldots \ldots \ldots \ldots \ldots \ldots . \ldots \ldots$

4. DISCUSSION

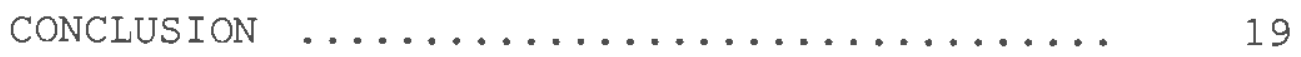

IMPLICATION $\ldots \ldots \ldots \ldots \ldots \ldots \ldots \ldots \ldots \ldots \ldots \ldots \ldots \ldots \ldots$

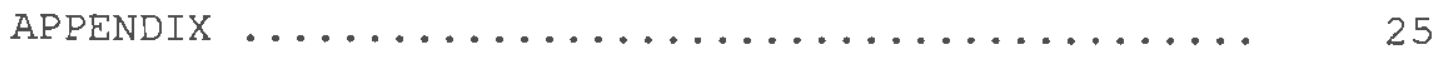

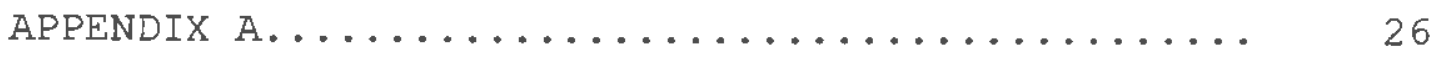

APPENDIX B.......................... 31

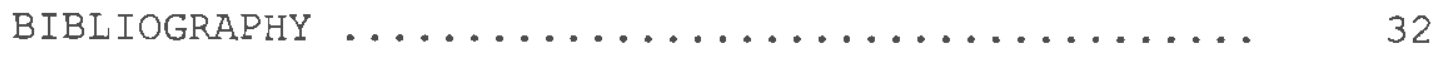




\section{LIST OF FIGURES}

FIGURE $\ldots \ldots \ldots \ldots \ldots \ldots \ldots \ldots \ldots \ldots \ldots \ldots \ldots \ldots \ldots \ldots \ldots \ldots \ldots$

1. CODING AND SORTING .............. 13 


\section{Introduction}

\section{Background}

Advanced educational opportunities at American colleges and universities, including both master and doctoral programs have long been appealing to prospective graduate students from all over the world. The population of international students has been steadily increasing and forms a substantial proportion of the total student population in American higher education during the last decade (Allameh, 1989). In the 1989/1990 academic year, over one-half (53.8\%) of the international students were from South and East Asia, primarily from China, Taiwan and Japan (Digest of Education Statistics, 1991). In 1989, international students earned almost 15 percent of all the graduate degrees conferred, including one-half of the doctorates conferred in mathematics and engineering (Alsalam \& Rogers, 1991).

International students, as people in cross-cultural and academic transition, do have problems different from their domestic peers. Significantly difficult situations await international students including language adequacy in cultural and academic settings, financial concern, academic performance, building personal and professional social relationships as well as locating information resources in a new environment, and adjustment to residential lifeli.e., food, climate, clothing, housing, transporting, recreation) (Klineberg \& Hull, 1979; Hull, 1978). 
It has been widely agreed that variations in the cultural background and characteristic of international students affect their problems and adjustment (Hull, 1978; Parr, Bradley \& Bingi, 1992). According to Hull's findings (1978), the coping of international students has much to do with their background. Therefore, it would be inappropriate to view all international students as a group when the issue is coping. Variables such as cultural background, field of study, and academic level have been used to describe different populations in the recent literature.

Apparently, most of the research about international students is problem-solving-oriented and, either directly or indirectly, regards students as defeated or at risk. Therefore, efforts have been made to assist international students with their adjustment, mostly by their receptive academic institutions. Some institutions try to help by providing handbooks, guidelines, orientation programs, or language programs. These approaches are designed to teach or suggest a set of "coping strategies" to international students.

An alternative would be thinking positively about international students and their adjustment. Despite these considerable difficulties, many international students are still functioning well in the host culture and gaining positive intercultural and academic experience in their own ways. Taking this positive perspective, it would be worthy to investigate the coping strategies originally used by 
international students before making suggestions. By understanding how and why they cope with massive adjustment in their daily lives, we might have a better chance to provide the effective facilitation they really need. As Alexander and Shaw (1991) proposed, "We believe that the successful outcome of the student's study in the United States can be enhanced by ..... support the coping efforts of the international student." (p.246)

\section{Review of Literature}

Studies regardilng international students is a collection of research from various disciplines with diverse concerns. Among these studies, the concern of coping strategies is fairly recent and comparatively subsidiary, while research in this line mainly focus on problems, variables, as well as the urgent call for solutions. Therefore, this review of literature starts with studies of international student adjustment and then moves into the studies of coping strategies. Studies of international students adjustment :

International students and their intercultural transition have been of interest to researchers in various fields, such as psychology, counseling, linguistic, communication and education, mainly because of their problems. In the 1970 's, several studies of international students focused on attitude, values, and experiences ( Klineberg \& Hull, 1979; Hull, 1978). These large scale 
pieces of research studies have provided valuable information for understanding international students.

As a starting point, research with international students as a homogeneous subject group has addressed some common problems awaiting all the international students such as finances, housing, food, English proficiency in both academic and social setting, academic performance, (Klineberg and Hull, 1979; Hull, 1978; Meloni, 1986), social relation, and health (Cho, 1988; McClaran \& Sarris, 1985). Other difficult experiences like homesickness, frustration, feeling of impotence, feeling of loneliness, and stress were also addressed but mostly handled by researchers in psychology and counseling.

While international students have many problems in common, their adjustments are affected by differences in their background and characteristics(Parr, Bradley \& Bingi, 1992). These multifaceted problems have revealed the complexity of the adjustment process. Some efforts have been devoted to identify variables in international student adjustment. These variables include background (cultural, family, personal), motives and length of stay, field of study and academic level, previous knowledge about USA and international experience (e.g. overseas travel), perceived English adequacy, the utilization of local resource and campus service, interaction with co-nationals and Americans (Hull, 1978; Mallinckrodt \& Leong, 1992; Parr, Bradley \& Bingi, 1992; Surdam \& Collins, 1984). 
After the common ground of problems and variables have been established, it apparently became inappropriate to view international students as a homogeneous group. Therefore, some researchers have used cultural background and field of study to as their subject variables (Adelegan \& Parks, 1985; Cho, 1988; Cho, 1990; Landau \& Laprade, 1983; MCClaran \& Sarris, 1985 ).

Along with identifying the problems and variables of the adjustment, there certainly were calls for a "cure". The searching for solutions arose from those institutions and lor subject fields which enrolled a considerable number of international students ( e.g.: UCLA, by Rust, 1981; NMSU, by Alawiye, 1982), (Alexander \& Shaw, 1991; Hobbs, 1989; Landau \& Laprade, 1983; Meloni, 1986). Several handbooks, guidelines and programs were generated to facilitate the international student adjustment by proposing sets of "coping strategies" which were usually developed from reviewing the problems and variables. Coping strategies actually used by international students, however, have not been fully explored in the literature.

Coping strategies of international students:

The issue of coping strategies of international students has emerged in research while the major concerns were to investigate the process and variables of their adjustment(Hull, 1978; Fontain, 1986; Mallinckrodt \& Leong, 1992) as well as to solve the problems by providing "coping strategies" (Hobbs,1989; Landau \& Laprade, 1983). Several 
handbooks, guidelines and programs have been developed to facilitate the coping of international students. Very often, these resources have mainly demonstrated the expectation in American education in terms of "coping strategies". A set of "coping strategies" was systematically introduced, usually in the form of "Do's and Don'ts", reflecting the prospects rather than applicable strategies(Hobbs, 1989). Some deliver their "coping strategies" by conducting an intensive program or training (Landau \& Laprade, 1983).

Recently, a new approach has arisen to investigate the coping strategies used by international students. With the belief in empowering students by supporting their efforts, research has been designed to promote understanding (Alexander \& Shaw, 1991). In order to improve understanding of individual students or groups of students, qualitative methods have the potential to obtain in-depth, detailed description from the students' perspective (Kuh \& Andreas, 1991). The emergence of this fairly new approach, coupled with the understanding-empowering philosophy and qualitative methodology, can supplement the conventional research methodologies, issues and foci.

\section{Statement of the Research Question}

This research was designed to answer the following research question: How do international students from Taiwan cope with their cross-cultural transition in American advanced education? The term, coping strategies, hereafter 
refers to strategies "utilized by an individual in a potentially stressful situation to establish emotional security while retaining self-esteem in a cultural setting distinct from one's own." (Hull, $1978 \mathrm{p} .11$ )

\section{Method \\ Subject}

The Sample consisted of foreign graduate students from Taiwan (holding a temporary visa: F-l) enrolled in a small state university on the northeastern coast of the United States of America during the Spring semester and Fall Semester 1992 .

Identified through the association of students from Taiwan, all 30 graduate students with F-l visa status were politely invited to participate after they were fully informed about this study. Twenty-four students agreed to participate in the study. The remaining 6 students were not interviewed because 4 were not available when the interviews were scheduled and 2 refused to participate.

The average age of the subjects was 30.96 at the time the research was conducted. Seventeen (70.8\%) of the subjects who arrived in America during the ages of 25-29, and 4 (16.78) of the subjects arrived over the age of 30 . Of the participants, 7 were female(5 single, 2 married with children) and 17 were male ( 7 single, 10 married, 6 with children). All 12 married students lived with their spouse ( and children, if any). 
Fifteen of the subjects were in the Doctorate programs ( 8 of them have earned their master degree in America) and 9 of the subjects were in Master programs. For completion of a master's programs, most students expected 2 years; for a doctoral programs after a master's degree, most students expected 4 to 5 years; for a doctoral program after a bachelor degree, most students expected 6 to 7 years. Of the participants, 15 planned to return to Taiwan after graduation or short-term practical training, 1 preferred to stay if possible, and 6 were undecided with major concerns about job markets, research environment, and children's' education.

Of all participants, 21 lived with co-nationals (from Taiwan) as housemates. All subjects spoke Chinese and English, and 21 spoke Chinese Taiwanese and English.

\section{Instrumentation}

A three-part questionnaire (see appendix A) was developed to obtain information about the perceived problems of the subjects in their cross-cultural experiences in their academic setting. Based on the problems addressed in the literature, this questionnaire was designed to be as open ended as possible to obtain the subjects' responses from their perspectives. The administration of this questionnaire was rather flexible because the objectives were (1) to prepare the subject for the following in-depth 
interview about their initial experience of studying in USA.; and (2) to give the interviewer a brief but holistic picture about each subject before and during conducting the interview.

Part one requested personal background information including gender, marital status, birth year, the arrival year in the US, arrival year at the university, major and degree the subject was working toward, expected year of graduation, basic information about their resident situations, preferred direction after graduation (return or stay), and language ability (bilingual or multilingual). Part two requested subjects to give their response to nine possible problematic categories based on their first six months experience in America. The nine categories were common problems that most international students might encounter in their sojourn according to previous research. Each category consisted of two parts : rating and comments. Subjects were directed to use a rating scale to indicate how often the problems had arisen from each category ranging from never (1) to always (4). For the comments, subjects were asked to briefly describe their experience in each category and allowed or indicate if they preferred to explain their responses in the interview. (The ratings served as an indicator to assist the researcher and were not analyzed quantitatively.)

Part three requested the subjects to answer three openended questions of what they consider (1) most unforgettable 
(2) most helpful / encouraging (positive factor), and (3) most worrying / discouraging, during their experience in America .

\section{Procedure}

\section{Data Collection}

(1) Asking for participation : According to the name list given by the association of students from Taiwan, the researcher called every potential subject to ask for their involvement. After giving a brief selfintroduction and reasons for calling, the researcher fully described the purpose and the content of this study, assured the confidentiality and explained the procedure (including the necessary cooperation in selfdisclosure, audio-recording, and estimated time), then asked for participation. With the approval granted, the researcher arranged the time and place for a private interview according to the subject's convenience.

(2) The personally administered questionnaire : Having been handed and asked to answer a questionnaire (Appendix A), the participants were told that they should just write down what came up in their mind, not worry about the format and the grammar, and feel free to ask any question at any time. They knew they could "tell the story later in the interview". Answering the questionnaire took about twenty minutes.

(3) The interview : After the participant finishing the questionnaire, the researcher skimmed it through, and 
then started the interview. (With the participant's permission, the interview session were audio-recorded. ) The interview followed but was not limited to this format : (a) identifying and understanding the problems, then (b) finding out the coping strategies applied under such circumstance, and (c) identifying the payoff of the strategies (for basic format, pleas see appendix B.). This format was repeatedly used in each category (e.g.: food, housing...) and in some cases, across the categories (e.g.: language problems vs. social interaction problems), according to the nature of the problems. The subjects were encouraged to use languages freely (Taiwanese, Chinese, English or combination) to encourage full disclosure during the interview. The accuracy of the mutual understanding was assured by the researcher checking the precise description in English with subjects and paraphrasing or summarizing the discussion from time to time. The average length of the interview was about eighty minutes.

The chronology of the interview followed the answers to the questionnaire, category by category. However, relevant deviations were allowed. The participant was asked to give a brief description about the problematic area, and then discuss specific problems under that category. An appropriate example was often requested to illustrate the situation. In this stage, a hidden agenda ( based upon the 
interviewer's knowledge about the target group and the intercultural transition) could be used to supplement the participant's initial reaction, but was never used to lead the direction of the answer.

Data Analysis

The following qualitative analysis procedure were conducted sequentially.

1. Profile : a profile for each participant was established by combining the written replies with the English transcription of the audio-taped interview. The profiles were sent to participants for review and correction to confirm that they appropriately represented the participants' perceptions. Only few minor changes were requested because of the change of facts.

With the agreement of the participants, these profiles were used for further qualitative analysis.

2. Coding : The information from all profiles was coded, assorted into three parts as problem, coping strategy and payoff. The process of coding is illustrated as Figure 1.

- Problem : this part contains problems and difficulties identified by participants. The problems were coded according to the subjects' perspectives / concerns.

- Coping strategy : this part contains the coping strategies used by participants while dealing with the problems. 
- Payoff : this part contains the consequence of the coping strategies. Items in this part served as footnotes for understanding effects of the coping strategies.

3. Summarizing : The coping strategies were summarized inductively.

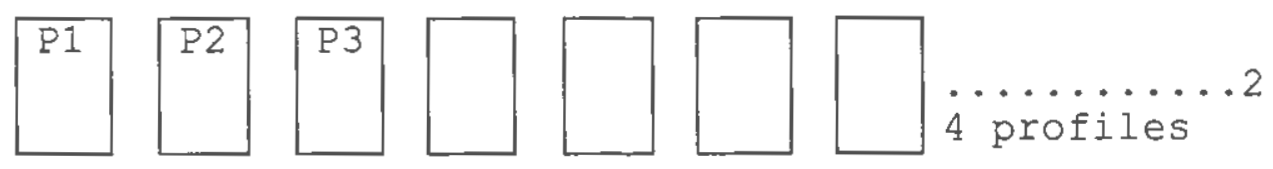

\section{PROFILE}

Problem

Coping Strategy

Payofi

Figure 1. Coding and first stage sorting : information from all profiles forms a big PROFILE then was assorted into three parts: problem, coping strategy and payoff. 
The findings of this research are presented in major categories consisting of strategies with similar approach, followed by a description and examples.

The primary approach of coping strategy used by Taiwanese students found in this research was individual problem-solving, along with information-seeking, supportseeking, and inaction.

1. Individual problem-solving: This kind of self-reliant strategy was found essential to all the subjects interviewed. Strategies such as self-study ("I had very low in-class comprehension, I heavily relied on selfstudy" ) trying harder (" I am a poor and slow reader in English. I usually read and review the reading assignment for two or three times"), exercising ("the Friday night ball-playing with other Taiwanese students is my major recreation"), commuting by foot (" I walk about two miles from my apartment to school then another two miles back from school, because I don't have a car and taking the bus is both inconvenient and costly here.") experienceand-learn ("the more I tried, the more I experienced, the more I learned"), prepare-and-Iearn ("Once I needed to mail a "certified mail", at the night before I went to the post office, I looked into dictionaries to find the relevant words, phrases, expressions I might need to use to talk to the postmaster. I spent two or three hours to 
prepare for it, this is the way I dealt with many difficulties : always be well-prepared and learn things through the preparation"), were typical examples. These strategies were broadly used to solve, (or minimize) the academic, language and residential life problems especially in early months of adjustment or before the subjects found alternatives. For example: while the concern was language insufficiency, subjects used key words and phrase, examples, picture drawing, audio-visual aids, body language to promote mutual understanding. 2. Information-searching : This kind of strategy was mainly used to reduce feelings of uncertainty, inadequacy, or impotence and to gain information before further decisions could be made. Two levels of searching were found: as personal network level and organization level.

- Personal network, including co-national seniors, peers, relatives residing in America, advisors, friends and others, and usually provided experiential information. In this case, co-national seniors were commonly identified as resourceful and important.

(The word "senior" was frequently used by Taiwanese students to refer to "those who came earlier" with considerable respect and gratitude.) strategies such as "always asking seniors first to get an idea" and "To ask is to learn" were used in cases of urgency ("what should I do?"), curiosity("Gee, I wonder what 
is that for?") as well as before decision-making("I need to know better").

- Organizational level information searching, including call-in and walk-in, usually provided authentic information about services, policies and regulations. (e.g.: A student called the health center: "I am a international student and my wife just got pregnant, what should we do?"; A student asked the staff in International student service Center: "I'm graduating this semester, can I legally work in America?")

While using information-searching strategies as ask-and learn, subjects were seeking for information, not support, from the person requested.

3. Support-seeking : This kind of strategy was used to acquire the support or assistance from one"s personal / professional support network. There were two sets of network identified by all participants, explained as follows:

- remote personal support network : this network consisted primarily family (parents and siblings), significant other (lover) and close friends in distance. Connections were maintained by regular phone calls or letters. Examples such as "sharing the experience", "knowing they are always there for you" and "keeping in touch reduce the homesickness" were representative. "Seeking or accepting financial 
support from home" was also common when subjects got no or only partial assistantship from the institution.

- local personal / professional support network : this network consisted primarily of spouses, advisors, colleagues, peers, and host friends nearby. Examples such as "just talking to somebody would make me feel better", "we always help each other (co-nationals)", and "my advisor has been very understanding and supportive" were typicaliy mentioned.

In general, subjects sought emotional support such as encouragement and understanding to reduce the stress. Subjects sought substantial support such as financial support and other assistance (favor-doing) to solve or minimize specific problems.

4. Inaction: Coping strategies in this category were implicit in behavior, but nevertheless important. While applying "inaction-strategies," subjects decided that they would benefit from "not acting" at that moment. Three kinds of inaction were used by subjects : attentive inaction, passive inaction, and temporary inaction.

attentive inaction : this term is used to describe the strategies of "preparing for accomplishment by learning through listening and watching", in this case, subjects remained inaction by choice. 
For example: In class discussions, subject $A$ didn't join the discussion: "Before I became ready to talk in the group, I thought the best thing I could do was just to concentrate on listening."

passive inaction : this term was used to describe" inaction due to impotence, powerlessness", in this case, subjects perceived no alternatives. For example: Even wishing to have some American friends, subject $B$ perceived no chance or didn't know how to make one, therefore no action was taken. temporary inaction: this term was used to describe "action delayed" phenomena. In this case, subjects intended to act, but needed some more time (reactiontime delay) or chose to do it later (intentional delay) .

For example: with additional doubts in his English proficiency, subject $\mathrm{C}$ would hold his questions and ask instructors or classmates after class. (e.g. : "I didn't know if others could understand my speaking", "I was not able to express my opinions directly and effectively, and I didn't want to waste their time.") In general, attentive and temporary inaction strategies have positive buffering effects so subjects don't have to confront their problems (e.g.: language or cultural barrier) directly in the public setting.

All the above were often interrelated with one another , since the coping process were rather dynamic than static. 
Multiple strategies could be applied at the same time with one dominate each situation according to the perceived priority of subjects.

\section{Discussion}

Conclusion

The findings in this study essentially provided a first step toward understanding the existing coping strategies of international students from Taiwan. The four major patterns of coping, including individual problem-solving, information-searching, support-seeking and inaction, generally reflected the potential and concerns as well as needs and limits of students.

Among all coping strategies, individual problem-solving strategies were often described as taking the responsibility by the subjects. The unanimous ones, such as self-study, trying harder, being well prepared, indicated that subjects have devoted a tremendous amount of time and energy to prepared themselves to be able to function, perform, and very often, outperform. All subjects admit that most of the pressure came from their self-set standard to be "outstanding" or at least "better than OK".

Despite of their good intention, however, working out solutions all by themselves sometime reflected their lacking of essential information or support due to their "foreigness" in this culturally different host environment. 
Information-searching strategies were constantly used to "make sense of this system" and "learn more about American culture". Most subjects indicated that even they have confidence to survive by themselves' efforts but they wish to know more about the American way ("that's what this sojourn for"). Getting necessary or sufficient information in either academic or daily life usually enabled subjects to do things with better guidance, assurance and, save their efforts.

support-seeking strategies were sometimes used to balance their overloaded self-demanding. The support from their advisors and colleagues usually relieves them from various difficult situations and empowers them to move further. Without exception, support from the institution level is considered only in case of problems involving immigration or administration regulations. On the other hand, the support from Taiwanese seniors and peers promotes their "helping-each-other" with most problems in residential life (initial accommodation and peer support) as well as academic suggestions. Consequently, the connections, owing to the instant and constant aid exchange among co-nationals, form and maintain the sense of community of their own. This kind of association, however, is identified by outsiders as "exclusively grouping", "flocking together", or "isolation from the host community", without much empathy. It is noticeable that failure of making host friends reinforces the inner bond among connationals. 
Inaction of various intention could be interpreted as a conservative approach to maintain the security. Inaction also gave subjects more flexibility to deal with their concerns instead of "being in the spotlight".

According to the characteristics of this particular cultural group, generalizing findings and discussion in this paper to students from Japan, Korea (Republic of ) and Singapore may be made possible after and only after careful investigation and specific cultural concern were conducted.

\section{Implication}

According to findings of this study, the following implications are recommended for institution, facilitator and further research:

For institutional facilitation

1. Informational assistance: Results indicate that international students develop many individual problem-solving strategies due to their insufficiency of essential information or support in this cultural reference. Therefore, providing information consultation may help students to know the system, the culture, the living in host environment (at least faster or easier), and consequently, promote their utilization of available resources.

The information service should cover what they should know as well as what they want to know. 
other than structured orientation and printed materials, more open-ended and interactive approaches such as (1) information hot line and (2) host friends could be helpful / useful for finding quick answer and / or locating relevant helpful resources for further inquiry for international students.

2. Host family arrangement: Many students express their desire to make friends with Americans but have no idea how to find one or how to start. It will be helpful if the university can initiate the first contact.

3. Language programs: Graduate level language programs are needed to facilitate for those desire to promote their Language adequacy in both social and academic setting.

( A thorough need assessment is strongly recommended. )

\section{For instructors / advisors:}

Findings reveal that international students benefit from instructor / advisor being supportive, understanding, friendly or at least willing to listen. The following suggestions are for instructors / advisors of international students:

1. The best way to show the concern to international students is "being specific and practical" (e.g.: "If you 
have any question, the best time to reach me is such and such.") instead of "being social and vague". Many instructors told students "stop me anytime if you don't understand the words I say." while the student perceived "Well, this is my first month, my listening comprehension is only 30g", "That's just not possible! The classmate will hate me!"

2. Let your international students know that you are available and willing to make necessary arrangement if the request is reasonable (e.g.: "I need some more time to do the examination").

3. If possible and appropriate, encourage international students to share their relevant experience with the class. By doing so, the instructor promote the international students' participation and contribution in the class("There is something I know and I can share with the class"), as well as broaden the international view for other students. This doing also possibly initiate the interaction between international students and their counterparts.

For future research:

Findings of this research indicate that (1) by investigating international students from specific background yield a holistic and vivid picture of this group and (2) the advantage of interviewer being familiar with the cultural background and /or dominate language of subjects 
may enhance the disclosure in the interview. These concerns can be best illustrated by the response of subjects: "It is not easy to talk about these complicated problems not to mention if you have to explain to a "foreigner" in English." As mentioned earlier, this study is to explore coping strategies used by students from one culture, more studies of students representing diverse cultural background are needed to establish a document serial. Such serial will be valuable resource for future research involving international students. 
APPENDIX 


\section{APPENDIX A}

\section{Thanks for your participation:}

Thank you very much for your participation. All the content of the survey and interview will be kept confidential by all means. Third parties do not have an access to personally identifiable records of information. (The participants' names will be replaced by a serial number or an alias for the research purpose.)

Once again, "THANK YOU VERY MUCH."

\section{About the research:}

- The goal of this study is to understand the adjusting process of the foreign graduate students in a university in USA. Using a questionnaire followed up by an interview, this research is conducted to gain a closer look at HOW they cope with What they encounter.

- The motivation for this study is to improve the environment to some extent so the foreign graduate students could enhance their performance and achievement according to their potential.

- This research will have cultural benefits, as it will help the foreign graduate students to be able to share their native-cultural and cross-cultural experience with the host community to increase the diversity. Their intercultural point of view, experience and reflection should benefit their colleagues in many ways.

\section{The questionnaire:}

The survey is designed to collect : (1) the basic information about the individual; (2) how the individual feels about those problems identified by the researchers as common problems for foreign students .

\section{The interview:}

- An audio-recorded interview, with the permission of the participants, may be conducted for more details.

- The transcript will be viewed and agreed upon the interviewee before the information from that interview is used.

- A copy of the written report of this research will be sent to participants upon request. 


\begin{tabular}{|r|r|r|l|}
\hline No: & & Gender: & \\
\hline Birth year: & & Major: & \\
\hline Marital status: & & Degree: & \\
\hline
\end{tabular}

- When were you first enrolled in a US educational institution ? What institution?

119

- Whom do you now live with ? (or alone?)

- When do you expect to finish this degree? 119

- Do you plan to go back to your country after graduation?

- Yes, I prefer to return to my country after graduation.

- Not really, I prefer to stay in USA.

- I don't have a preference.

major concern:

- Language ability: (cultural background)

Please list all the language(s) that you can use to communicate with, in the order of your proficiency

1.

2.

3.

4.

5.

6. 
The following is a list of possible problematic categories that you as a foreign graduate students might have encountered. Answering questions based on your first six months experience here, otherwise, please circle the category and specify the time when the category became most problematic to you. If you don't feel comfortable with the rating, or prefer to explain your experience in the interview, please put [int.] instead.

\section{Rating Scale:}

How often did you worry about this kind of problems ?
1 for: never
2 for: once in a while
3 for: more often than not
4 for: always

\section{Comments:}

How would you describe your experience? (How do you feel about it?) Please use three or more adjectives relevant to express your experience with each category.

\section{Food :}

Rating: ; Comments :

Clothing :

Rating: ; Comments:

Housing:

Rating: ; Comments:

Transportation: Rating: ; Comments :

Schooling : Rating: ; Comments:

Recreation: Rating: ; Comments :

\section{Finances}

Rating: ; Comments:

Language (English proficiency)

for academic purpose

Rating:

for daily life

; Comments:

Rating : ; Comments :

for social gathering

Rating:

for specific purpose

Rating: - Comments: ; Comments:

Social interaction Rating: Comments:

Other: i Comments: 
1) In this period of time, what event do you remember most? The most unforgettable thing was:

2) What helped you the most ? What encouraged you the most?

3) What worried you the most? What discouraged you the most? 
The University of Rhode Island

Department of Education:

705 Chafee Social Science Center

Kingston, RI 02881

The Coping Strategies of Taiwanese Students at an American University

\section{CONSENT FORM FOR RESEARCH}

- I have been asked to take part in a research project described below. The researcher will explain the project to me in detail. I should feel free to ask questions. If I have more questions later, Litsong $\mathrm{Lu}$, the person mainly responsible for this study, (401) 782-1787, will discuss them with me.

- I have been asked to take part in the study which is proposed to understand the foreign student's concern and coping strategies toward the cross-culture adjustment problems.

- If I decide to take part in this study here is what will happen: (1) the researcher will set a 90minute appointment according to my convenience (2) I will complete a questionnaire about my demographic information and my general opinions as a foreign students for cross-culture adjustment and (3) an follow-up interview about how I deal with those problems will be condueted and audio-recorded only under my permission. (4) A copy of the translation will be sent to me in 10 days after the interview. I will be able to review, make necessary corrections and give it back with my validation before the information is used for the study.

- Although there will be no direct benefit to me for taking part in this study, the researcher may learn more about the foreign student's perspectives and coping strategies while facing those problems awaiting most foreign students. It is very possible that this research will give the feedback to the university community from foreign students' perspectives and generate some institutional implications.

- My part in this study is confidential. None of the information will identify me by name. All records will be serial numbered and kept only to researcher's current study.

- The decision whether or not to take part in this study is up to me. I do not have to participate. If I decide to take part in the study, I may quit at any time. Whatever I decide will in no way penalize me. If I wish to quit I simply inform Litsong Lu (40I) 782-1787 of my decision.

- If I am not satisfied with the way this study is performed, I may discuss my complain with Litsong Lu or with Dr. James Barton (40I) 792-5916, anonymously, if I choose. In addition, I may contactthe office of the Vice Provost for Reasearch, 70 Lower College Road, University of Rhode Island, Kingston, Rhode Island, (401) 792-2635

- I have read the Consent Form. My questions have been answered. My signature on this form means that I understand the information and I agree to participate in the study.

Signature of Participant

Typed/printed Name

Date
Signature of Researcher

Typed/printed Name

Date 


\section{APPENDIX B.}

Basic interview format

$x$ : categories (food, clothing, housing, transportation...)

Y: examples

Z: problems

(a) identifying and understanding the problems:

e.g.: "About X, what is it alike? How would you describe it?"

"What's your experience in $x "$

"About what you've just described, could you be more specific?"

"could you give me some examples?

"Tell me more about $Y . "$

"From $Y$, it seemed that $Z$ has been a problem for you in $x$, could you tell me how did $z$ affect you?

(b) finding out the coping strategies applied under such circumstance:

e.g.: "How did you deal with z?"

"Under such circumstance as $Z$, what did you do to get away with this kind of problems / make things better?

(c) identifying the payoff of the strategies

e.g.: "How did things turn out? any better?"

"Did that help or not?" 


\section{BIBLIOGRAPHY}

Adelegan, F. O. \& Parks, D. J. (1985). Problems of transition for African students in an American university. Journal of College student Personnel, $26(6), 504-508$.

Alawiye, O. \& Westbrook, G. L. (1982). NMSU foreign student perceptions: A transactional evaluation. New Mexico state University. (ERIC Document Reproduction Service No. ED 233 622)

Alexander, M. A. \& Evelyn, S. (1991). International students at a college of nursing: Concerns and coping. Journal of American College Health, 39, 245-247.

Alsalam, N. \& Rogers, G. T. (1991). The Condition of Education.

Altbach, P. G. (1991). Impact and adjustment: foreign students in comparative perspective. Higher Education, $\underline{21}, 305-323$

Cho, S. (1988). Predictive factors of stress among international college students. Doctoral Dissertation, University of Missouri.

Cho, W. (1990). An investigation of feelings of loneliness among Chinese students in the University of Texas at Austin. (ERIC Document Reproduction Service No. ED 333 304) 
Digest of Education Statistics (1991). Washington, DC:

United States Department of Education.

Dillard, J. M. \& Chisolm, G. B. (1983). Counseling the international students in a multicultural context. Journal of College Student Personnel, 1983, March, 101105 .

Fontaine, G. (1986). Roles of social support systems in overseas relocation Implications for intercultural training. International Journal of Intercultural Relations, $10(3), 361-378$.

Furnham, A. (1987). The adjustment of sojourners. In Y. Y. Kim \& W. B. Guykunst, (Eds.), . Cross-cultural

Adaptation: Current approaches (pp.42-61). Beverly Hills, CA: Sage

Gordon, E. W., Miller, F., \& Rollock, D. (1990). Coping with Communicentric bias in knowledge production in the social sciences. Educational Research, 19(3), 14-19. Heikinheimo, P. S. \& Shute, J. C. M. (1986). The adaptation of foreign students: Student views and institutional implications. Journal of College student Personnel, $27(2), 399-406$.

Hobbs, S. (1989). Strategies for succeeding in a U.S. university: A handbook for incoming foreign students. Bloomington, IN : Indiana University, School of Public and Environmental Affairs. (ERIC Document Reproduction Service No. ED 314 322) 
Hood, M. A. G. (1983) Professional integration: A guide for students from the developing world. Washington, DC:

National Association for Foreign Student Affairs, (ERIC Document Reproduction Service No. ED 249 845)

Herbert, W. (1981). Abroad in the U.S.: Foreign students on American campuses. Educational Record, 62 (3) 68-71.

Hull, W. F. (1978). Foreign students in the United States of America : coping behavior within the educational environment. New York: Praeger.

Kim, Y. Y. (1987). Preface. In Y. Y. Kim \& W. B. Guykunst,(Eds.),. Cross-cultural Adaptation: Current approaches (pp.7-41). Beverly Hills, CA: Sage.

Klineberg, O., \& Hull, W.F. (1979). At a foreign university: An international study of adaptation and coping. New York :Praeger.

Kuh, G. D. \& Andreas, R. E. (1991). It's about time: Using qualitative methods in student life studies. Journal of College Student Development, 32, 397-405. 
Landau, J. \& Laprade, R. (1983). Coping strategies: Preparing foreign graduate students for professional academic programs. Paper presented at the 17th Annual Convention of Teachers of English to Speakers of Other Languages. Toronto, Ontario, Canada. (ERIC Document Reproduction Service No. ED 230 058)

Mallinckrodt, B. \& Leong, F. T. L. (1992). International graduate students, stress and social support. Journal of College Student Development, 33, 71-78.

McClaran, D. M. \& Sarris, R. A. (1985). International students and health: Their perceptions, behaviors and health care utilization. (ERIC Document Reproduction Service No. ED 257 802)

Meloni, C. F. (1986). Adjustment problems of foreign students in U.S. college and universities. (Contract No. 400-82-009). Washington, DC: ERIC Clearinghouse on Languages and Linguistics. (ERIC Document Reproduction Service No. ED 276 296)

Parr, G., Bradley L. \& Bingi, R. (1992). Concerns and feelings of international students. Journal of College Student Development, 33, 20-25. 
Rust, V. D. (1981). The foreign student at the UCLA graduate school of education. Los Angeles, CA : University of California Los Angeles. (ERIC Document Reproduction Service No. ED 213290 )

Surdam, J. C. \& Collins, J. R. (1984). Adaptation of International Students: A cause for Concern. Journal of College Student Personnel, 1984, May, 240-244.

Whitt, E. J. (1991). Artful science: A primer on qualitative research methods. Journal of College student Development, 32, 406-415.

Zikopoulos, M. (1989). Profile 1987-1988. Detailed analyses of the foreign student population (Report No. ISBN87206-177-9). New York: Institution of International Education. (ERIC Document Reproduction Service No. ED $312980)$ 